\title{
Chuquicamata full-scale field deposition trial
}

\author{
B Pirouz ATC Williams Pty Ltd, Australia \\ S Javadi ATC Williams Pty Ltd, Australia \\ P Williams ATC Williams Pty Ltd, Australia \\ C Pavissich ATC Williams Pty Ltd, Chile \\ G Caro Codelco, Chile
}

\begin{abstract}
A large-scale field deposition trial was carried out at the Chuquicamata mine's Talabre Tailings Storage Facility (TSF) in Chile to study the achievable beach slope with the current tailings in the absence of further thickening. The tailings received at the Talabre TSF are a mix of tailings from two different operating mines; Chuquicamata $(\mathrm{CH})$ and Ministro Hales $(\mathrm{MH})$.

The field deposition trial was run with a total discharge flowrate of $100 \mathrm{~L} / \mathrm{s}$ from two outlets each discharging $50 \mathrm{~L} / \mathrm{s}$. The average as-received solids content of the slurry during the field trail was 52\% ranging from $56.5-40.8 \%$ (solids by weight).

The trial was run for 56 days from early August to early October 2014 with continuous tailings discharge for eight hours per day. The limitation on discharge time was to prevent rapid initial build-up and possible mass slumping which would interfere with the interpretation of the results. Nevertheless the scale of the trial was such that 'continuous' discharge conditions established quickly at the beginning of each deposition day, and the trial is considered to be representative of continuous discharge conditions.

As expected, discharge of tailings resulted in the formation of a plunge pool at the impact area of the slurry stream at the head of the beach then self-formed channels that developed on the beach as the slurry left the plunge pool. The tailings beach that forms by this mechanism is similar to a full-size stack. This is a clear distinction from smaller scale deposition trials that are often reported which involve the deposition at very low flow rates or of discrete batches of tailings which result in a beach formed by layers of sheet flow.
\end{abstract}

The preliminary results and findings from the monitoring and observations of this trial deposition including the achieved beach slope are presented and discussed in this paper.

\section{Introduction}

In 2011 a prefeasibility/conceptual design study was undertaken by ATC Williams Pty Ltd (ATCW) for future tailings disposal at the Talabre TSF at the Chuquicamata copper mine in Chile. The mine has been in operation since 1910. Until 1951 it was a leaching operation before changing to sulphide flotation. The Talabre site is a wide gently sloping valley. An embankment forms the TSF impoundment. The current disposal method to Talabre is single point discharge down-valley to the embankment. Future life-of-mine tonnage to 2057 is 6,000 Mt. This could not be accommodated using the existing disposal method and the study recommended a switch to the central thickened discharge (CTD) method. The current TSF area is around $50 \mathrm{~km}^{2}$ which will increase to over $90 \mathrm{~km}^{2}$.

One of the key parameters in the design of a thickened tailings stacking scheme is the achievable beach slope.

Different theories and models exist for the nature of thickened tailings beach formation and development and also for prediction of the associated beach slope. A review of these theories and models is given by Williams (2014). 
The approach adopted in the current study is based on the equilibrium channel slope model, which was originally developed by Williams and Meynink (1986) and re-stated by Pirouz et al. (2005) and Fitton et al. (2007).

The theory behind the model, which is based on the hydraulics of self-formed, turbulent flow channels and which postulates that the beach slope will equal the equilibrium slope of such channels, suggests that the slope is determined by two main influencing factors:

- rheology (which reflects the effect of solids concentration, particle size distribution and mineralogy); and

- discharge flowrate.

The development of self-formed channels on the stack only occurs if the tailings are discharged continuously (Pirouz et al. 2014). Therefore it is essential that any trial for the study of tailings beaching behaviour be run with continuous discharge of tailings into the deposition area for a long enough time to allow the channels to form (similar to the full-scale condition) and not by deposition of very low (laminar) flow rates or discrete batches of tailings. These latter approaches result in measuring a beach slope value that is significantly steeper than the actual stack.

In 2013 Pirouz et al. (2013) presented a paper on the results of pilot plant flow-through flume testing for beach slope evaluation at the Chuquicamata mine. The maximum flowrate in the pilot plant flume testing was limited to $18 \mathrm{~L} / \mathrm{s}$.

Analysis of the pilot plant test results suggested that if the flow from the existing thickeners with a solids content of $57 \%$ was split down to individual discharges of the order of $50 \mathrm{~L} / \mathrm{s}$, an average beach slope of $1.5 \%$ would be achievable.

A larger-scale field deposition trial with the current tailings which are a mix of $73.7 \% \mathrm{CH}$ and $26.3 \% \mathrm{MH}$ was undertaken to confirm this.

The main purpose of the current 'full-scale' field trial was to extend the results of the previous pilot plant trial, and provide additional support for the estimated value for this important design parameter.

The trial is referred to as a 'full-scale trial' because the discharged flowrate per outlet in the trial is exactly the same as the design for the full-size stack.

It should be noted that at the time of the pilot plant testing in 2011 the $\mathrm{MH}$ mine was not commissioned and the available tailings for pilot plant test work was from the $\mathrm{CH}$ mine only.

\section{$2 \quad$ Site facility and set-up}

The field deposition trial was carried out at the so called 'Area $8 A^{\prime}$ located at the northwest side of the Talabre TSF. Figure 1 shows the Talabre TSF and the location of the trial area.

The general arrangement for the site facility and set-up are shown in Figure 2. The main tailings pipeline which transports the tailings from the concentrator plant to Talabre is a steel pipe with nominal diameter of $660 \mathrm{~mm}$. A HDPE ND $250 \mathrm{~mm}(I D=219 \mathrm{~mm}$ ) off-take pipe from the main tailings pipeline was used to transport the required tailings flow to the field trial. 


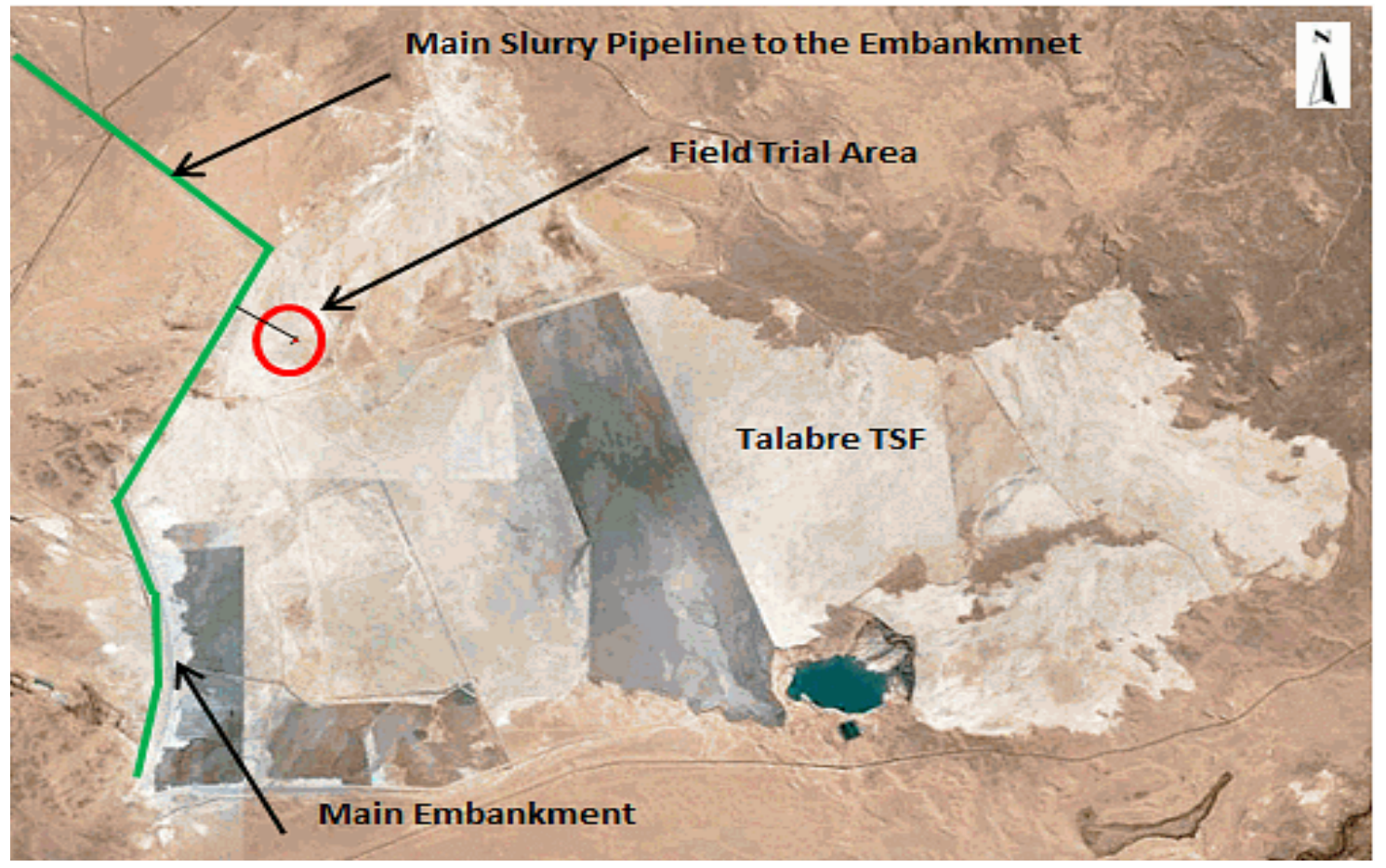

Figure 1 Field deposition trial location

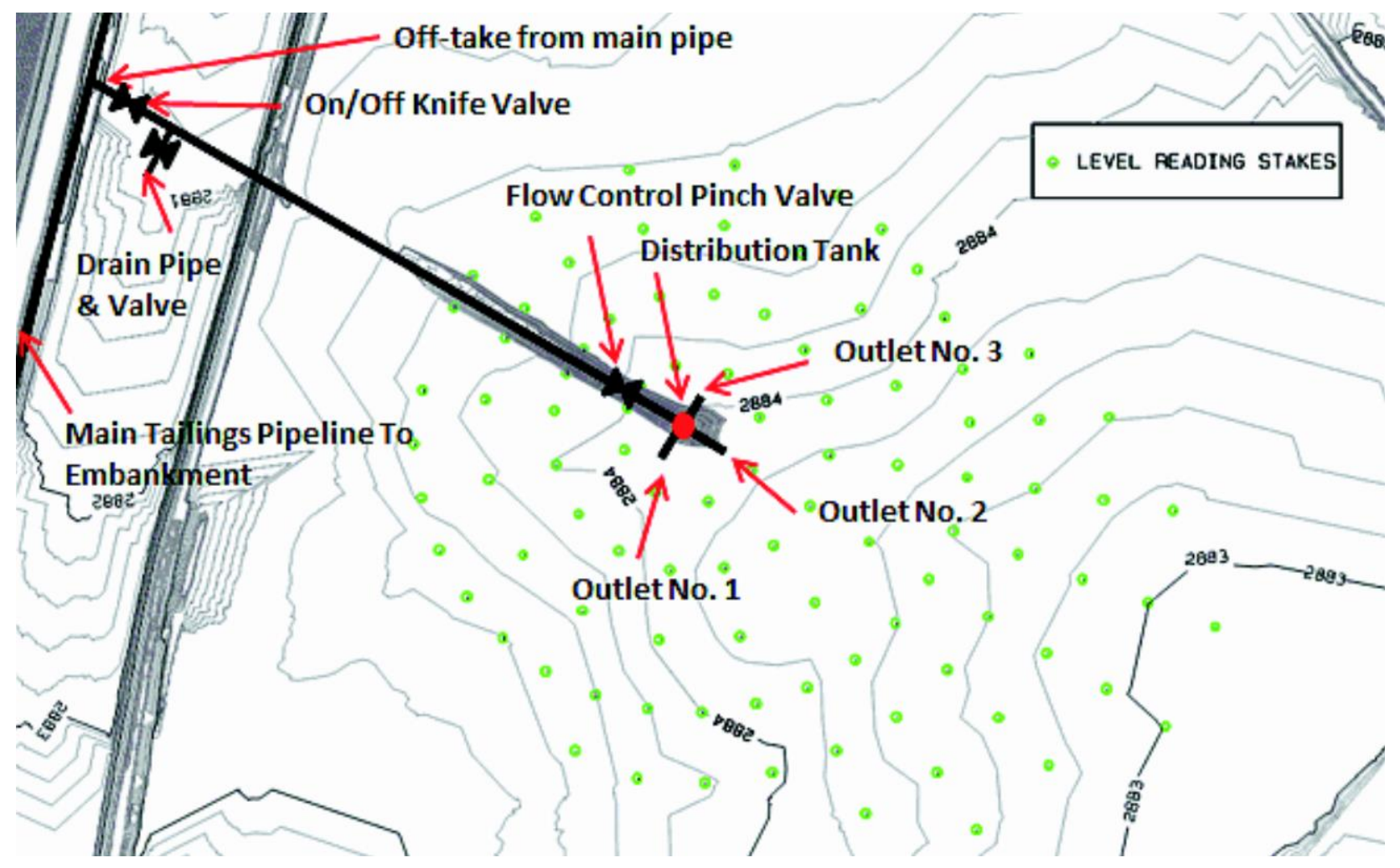

Figure 2 General arrangement and set-up for site facility

The detail of the arrangement for the connection of the off-take pipe to the main pipe is shown in Figure 3. As shown in Figure 3 the HDPE pipe is connected to the main pipeline via a size reducer. An on/off knife valve is installed at the downstream of the reducer. A drain outlet and valve were also included for drainage of the system at the end of each day of operation. 


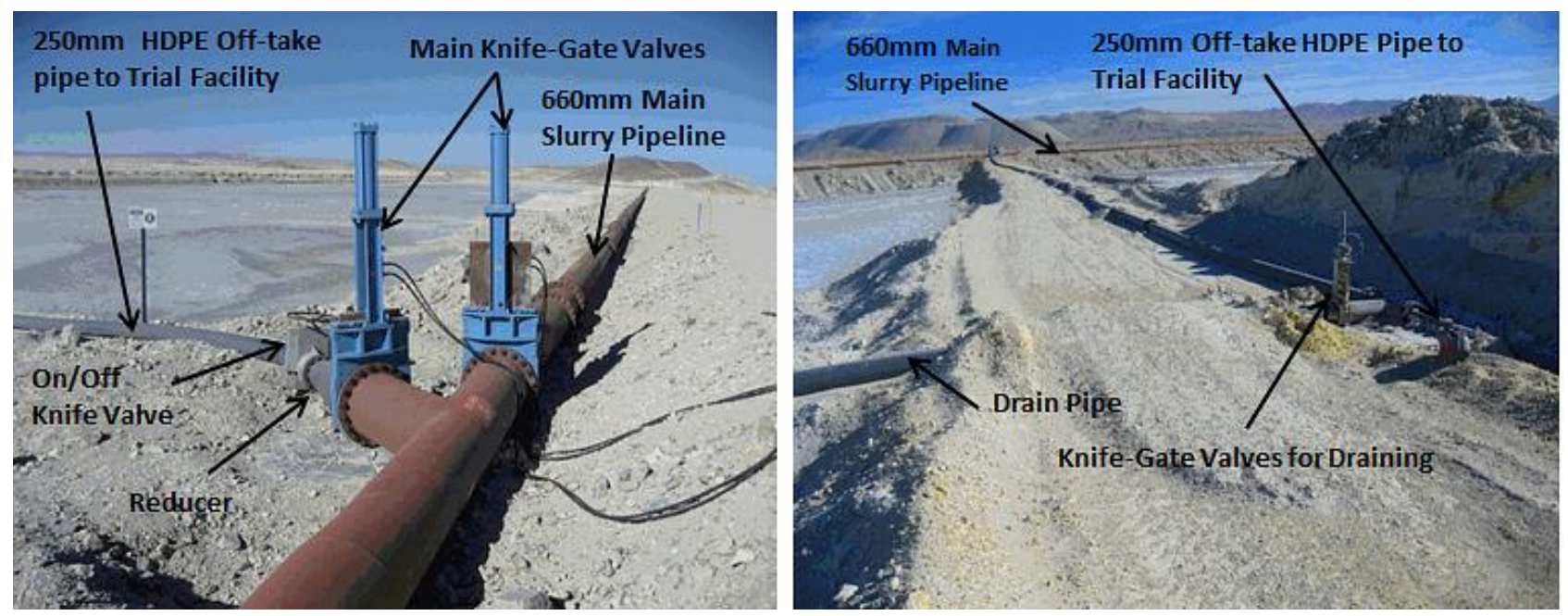

\section{Figure 3 Arrangement of off-take pipe connection to the main tailings pipeline}

The off-take pipe was placed on a causeway constructed from dry tailings. At the end of the causeway the HDPE off-take pipe was connected to a distribution tank. The details of the distribution tank are shown in the four views in Figure 4.
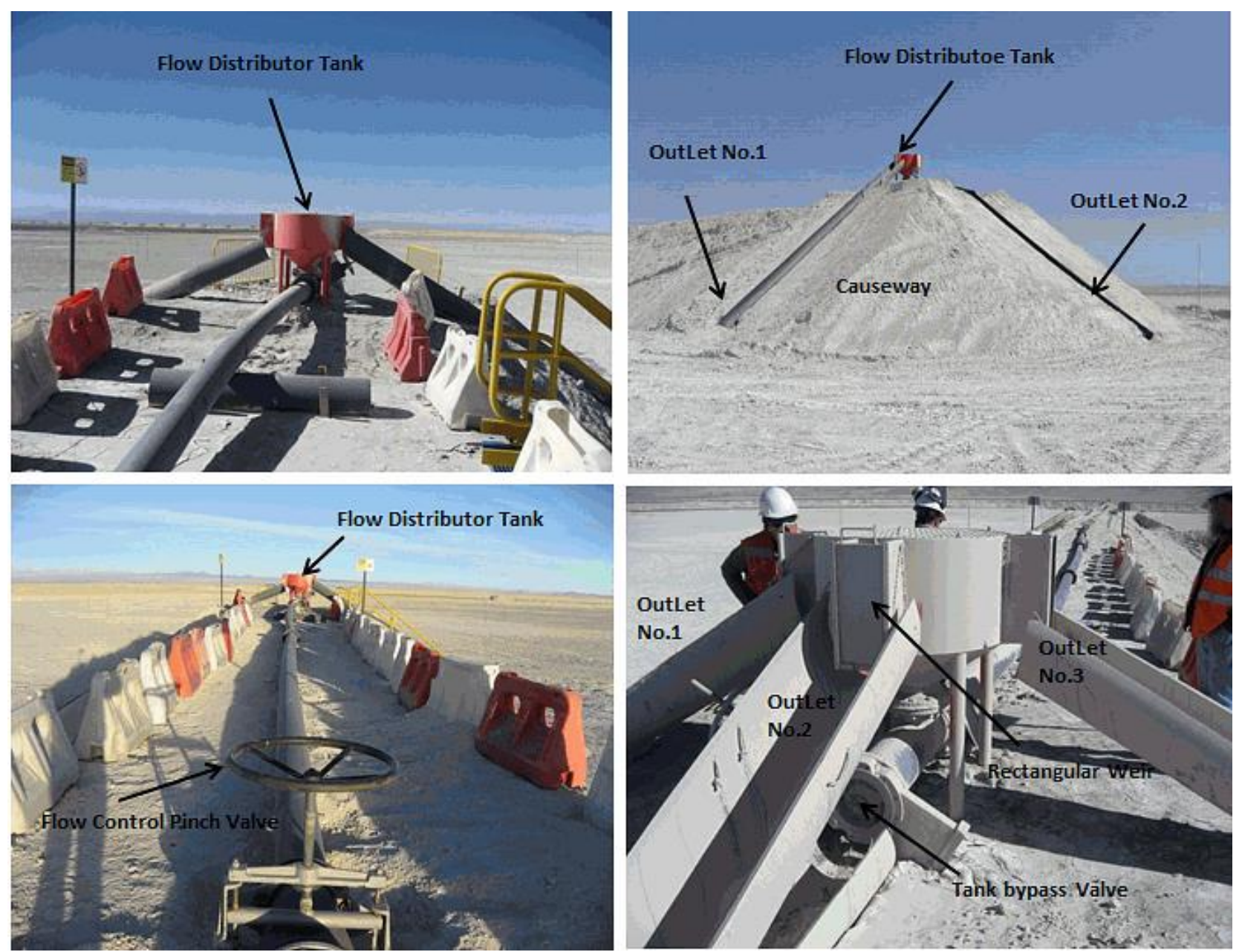

Figure 4 Arrangement of the flow distribution tank

The flow distribution tank was equipped with three overflow rectangular weirs acting as flow control structures. The outlet weirs had a crest width of $200 \mathrm{~mm}$, a crest length of $200 \mathrm{~mm}$ and a maximum height (for potential hydrostatic head build-up) of $500 \mathrm{~mm}$. Each rectangular weir was equipped with a sliding gate 
which could be used to block off the outlet. During the operation of the deposition trial only outlets No. 1 and No. 3 were used.

The flow rate to the distribution tank was controlled by a pinch valve installed at about $20 \mathrm{~m}$ upstream of the tank. The off-take pipe and the flow control system were designed to be operated with flow rates between 100-150 L/s.

The HDPE pipe at the connection to the distribution tank had an outlet valve which could be used to bypass the distribution tank if required.

As shown in Figure 4, in order to protect the causeway from erosion due to tailings flow, a half-pipe channel section was installed on the sloping face of the causeway below each outlet to carry the tailings flow to the deposition area.

\section{Operation of trial stack and site facility}

The trial was run for 56 days from early August to early October 2014 with continuous tailings discharge for eight hours per day. The limitation on discharge time was to prevent rapid initial build-up and possible mass slumping which would have interfered with interpretation of the results.

During each day's operation, the tailings were discharged from two of the overflow weirs (outlets No. 1 and No. 3) with a flow rate of $50 \mathrm{~L} / \mathrm{s}$ from each to the deposition area. Figure 5 shows the distribution tank in operation.
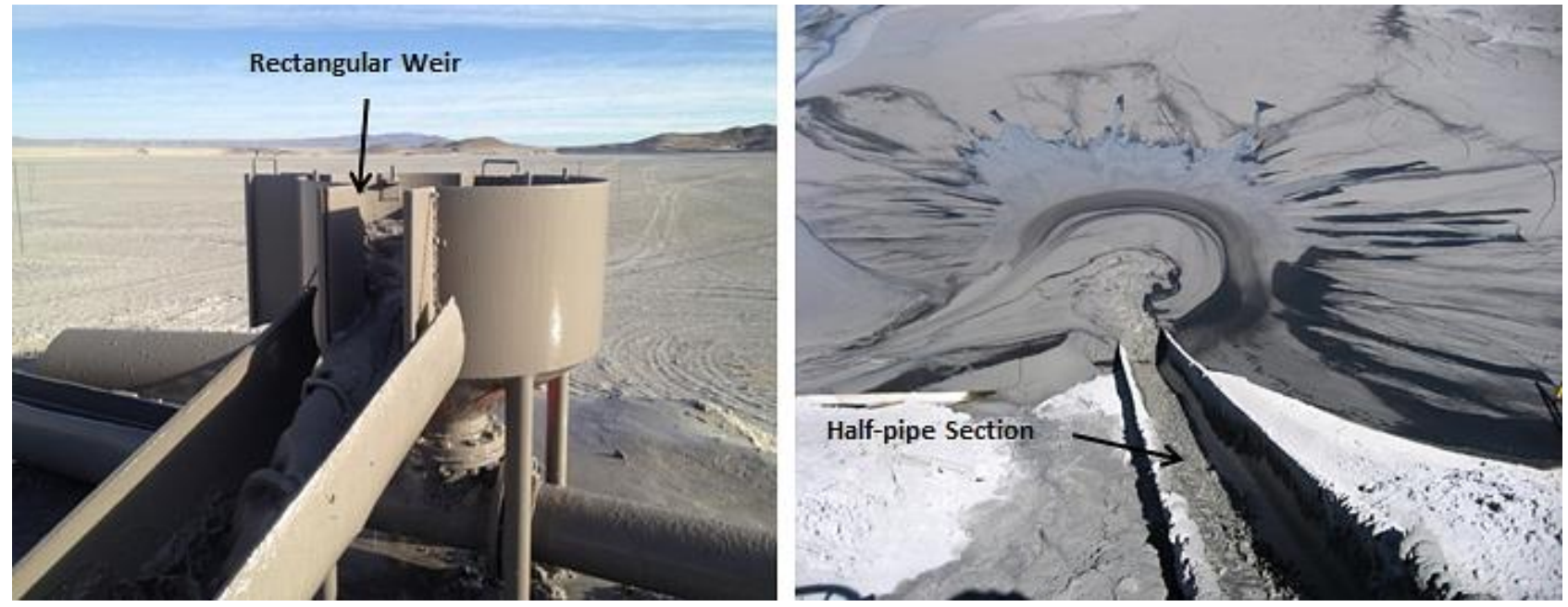

\section{Figure 5 Distribution tank in operation}

The daily eight-hour operation of the stack provided enough time for the 'continuous' discharge conditions (i.e. channelisation of the flow on the developing beach) to establish quickly at the beginning of each deposition day similar to a full-size stack. At the end of each day the system was shut down, drained (by using the drain pipe and valve) and ready for the next day.

\section{$4 \quad$ Monitoring and measurements}

The following measurements, monitoring and data collection were conducted during daily operation of the trial.

\subsection{Measurement and monitoring of flow rate}

The monitoring and measurement of flow rate was done by using Dynasonics DXN ultrasonic flowmeter sensors and a portable readout unit installed $10 \mathrm{~m}$ downstream of the flow control pinch valve $(10 \mathrm{~m}$ upstream of the distribution tank). Figure 6 shows the set-up for flow measurement. 

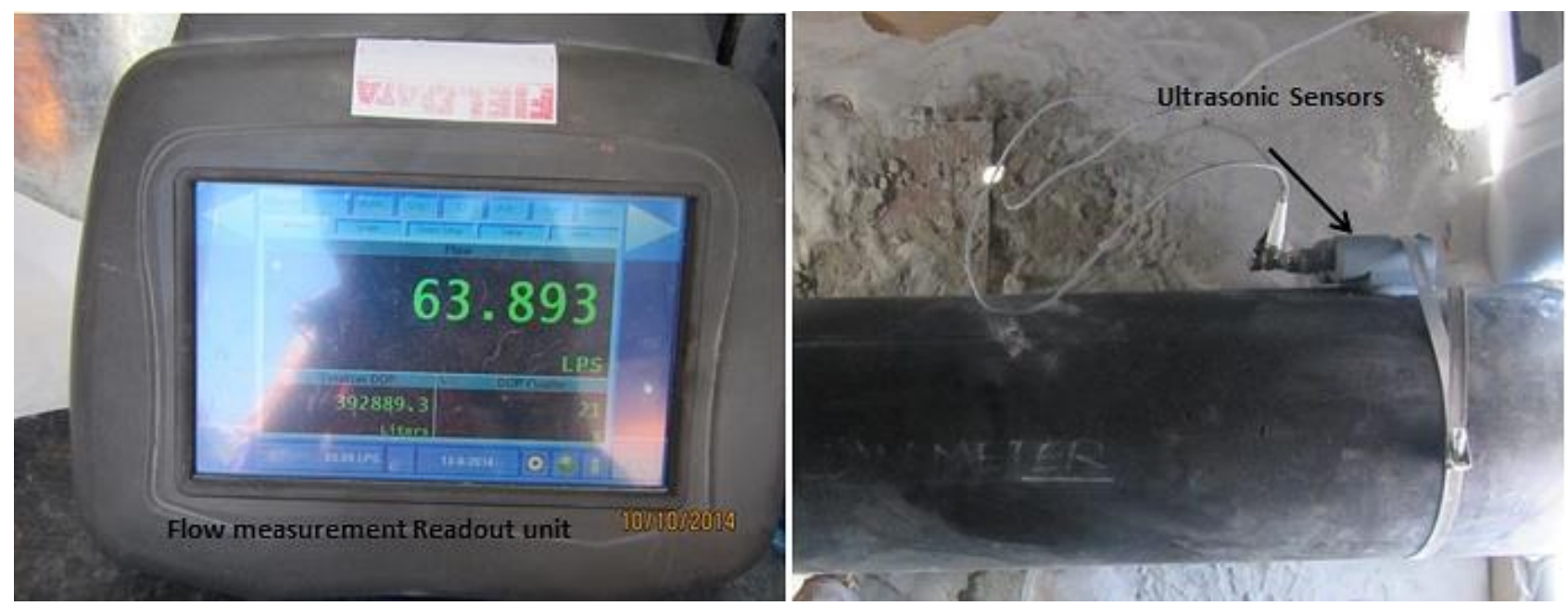

Figure 6 Dynasonics DXN ultrasonic flowmeter sensors and readout unit

During the daily operation of the trial any deviation of flow rate from $100 \mathrm{~L} / \mathrm{s}(2 \times 50 \mathrm{~L} / \mathrm{s})$ due to variation of the upstream conditions was recorded and the flow was adjusted back to $100 \mathrm{~L} / \mathrm{s}$ by using the flow control pinch valve.

\subsection{Measurement of deposition height and beach development}

Tailings deposition height and developing beach profile over the period of the trial were monitored and recorded on a daily basis.

Level reading stakes were installed to the estimated extent of the footprint area of the trial stack with an average interval of $50 \mathrm{~m}$. The locations of the stakes are shown in Figure 2. At the end of each day the tailings level next to the stakes was recorded.

In addition to the daily record of the level reading stakes, a full survey of the developing beach was also carried out twice weekly by using a TOPCON 3D laser scanner machine. Figure 7 shows the level measurement instruments.

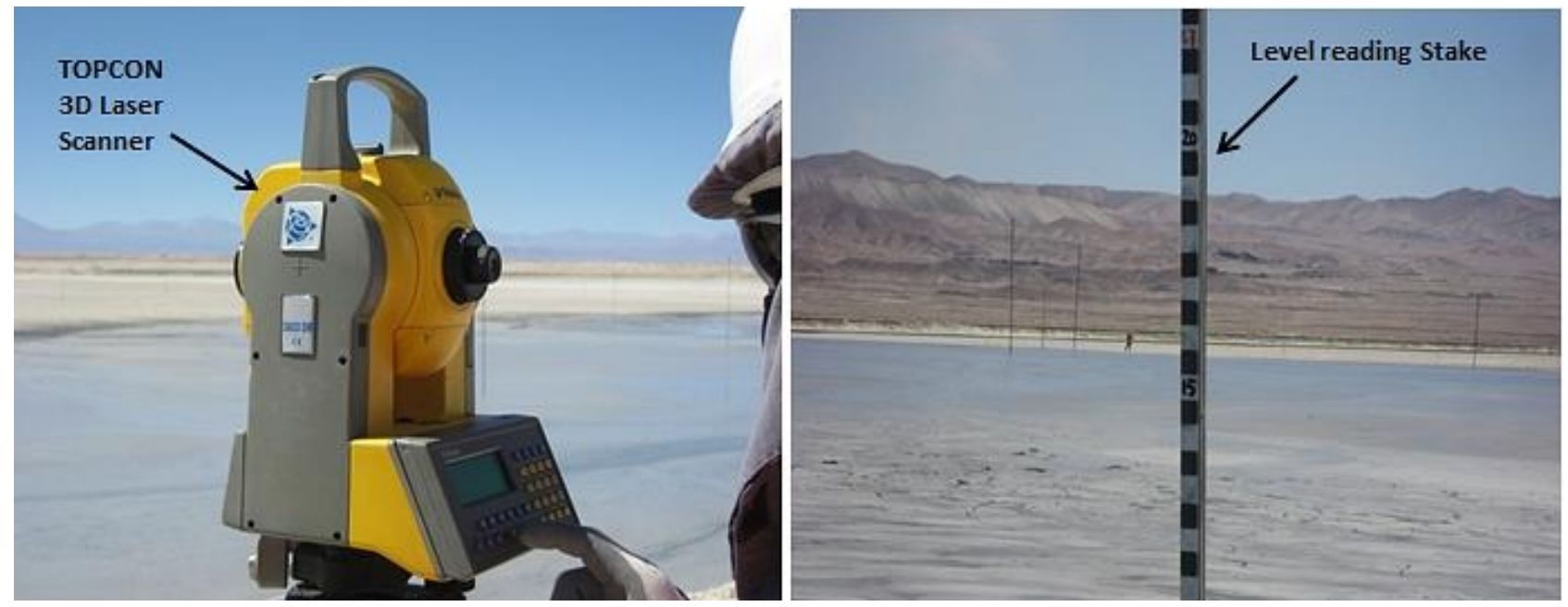

Figure 7 3D laser scanner and level reading stakes

\subsection{Measurement of solids content}

Three daily samples (one at the beginning of the day, one at the middle of the day and one at the end of the day) were taken from the distribution tank for oven drying and solids content check. 


\subsection{Measurement of rheology}

Two daily samples (one at the start and one at the end of the day) were taken from the distribution tank for rheology testing. The rheology of the samples was measured using a Thermo Haake VT550 rheometer.

\section{$5 \quad$ Recorded data and results}

The daily variation of the solids content of the tailings received at the field trial is plotted in Figure 8 . As can be seen, the solids content of the slurry varied between $40.8-56.5 \%$ with an average value of $52.1 \%$.

The variation of rheology of the slurry received at the field trial versus the solids content of slurry sample is plotted in Figure 9 . The rheological parameter shown in this plot is $t_{100}$ which is defined as the shear stress at a shear rate of $100 \mathrm{~s}^{-1}$.

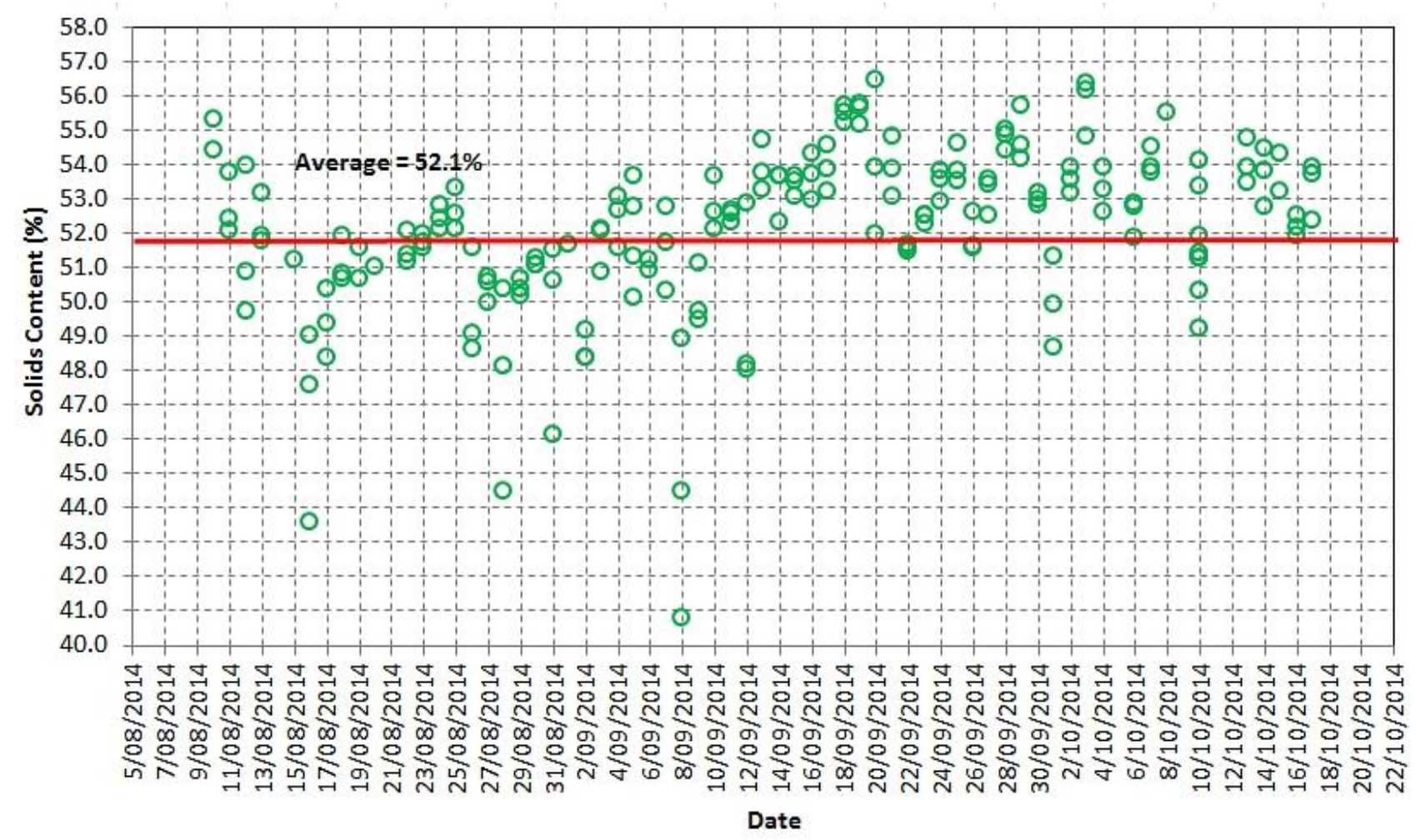

\section{Figure 8 As-received solids content of the slurry during the field trial period}

As can be seen in Figure 9 the variation of slurry rheology for any given solids content is considerable. This is assumed to be due to the variability of the feed to each of the $\mathrm{CH}$ and $\mathrm{MH}$ concentrator plants and also the proportion of $\mathrm{CH}$ and $\mathrm{MH}$ tailings streams in the mix at different times.

To compare the rheology of the tailings received at the field trial with the tailings used during the pilot plant testing in 2011 (Pirouz et al. 2013), seven samples were taken during the field trial at different times and were thickened to higher solids content and tested. Figure 10 shows the results of this testing in comparison to the rheology of the tailings during the pilot plant test work. It can be seen in Figure 10 that the rheology of the tailings used in the pilot plant test work is lower than the rheology of the tailings in the field trial. This expected to be due to variation in mineralogy of orebody and also the effect of ore from $\mathrm{MH}$ mine which is a new open cut with high clay content at the start-up. 


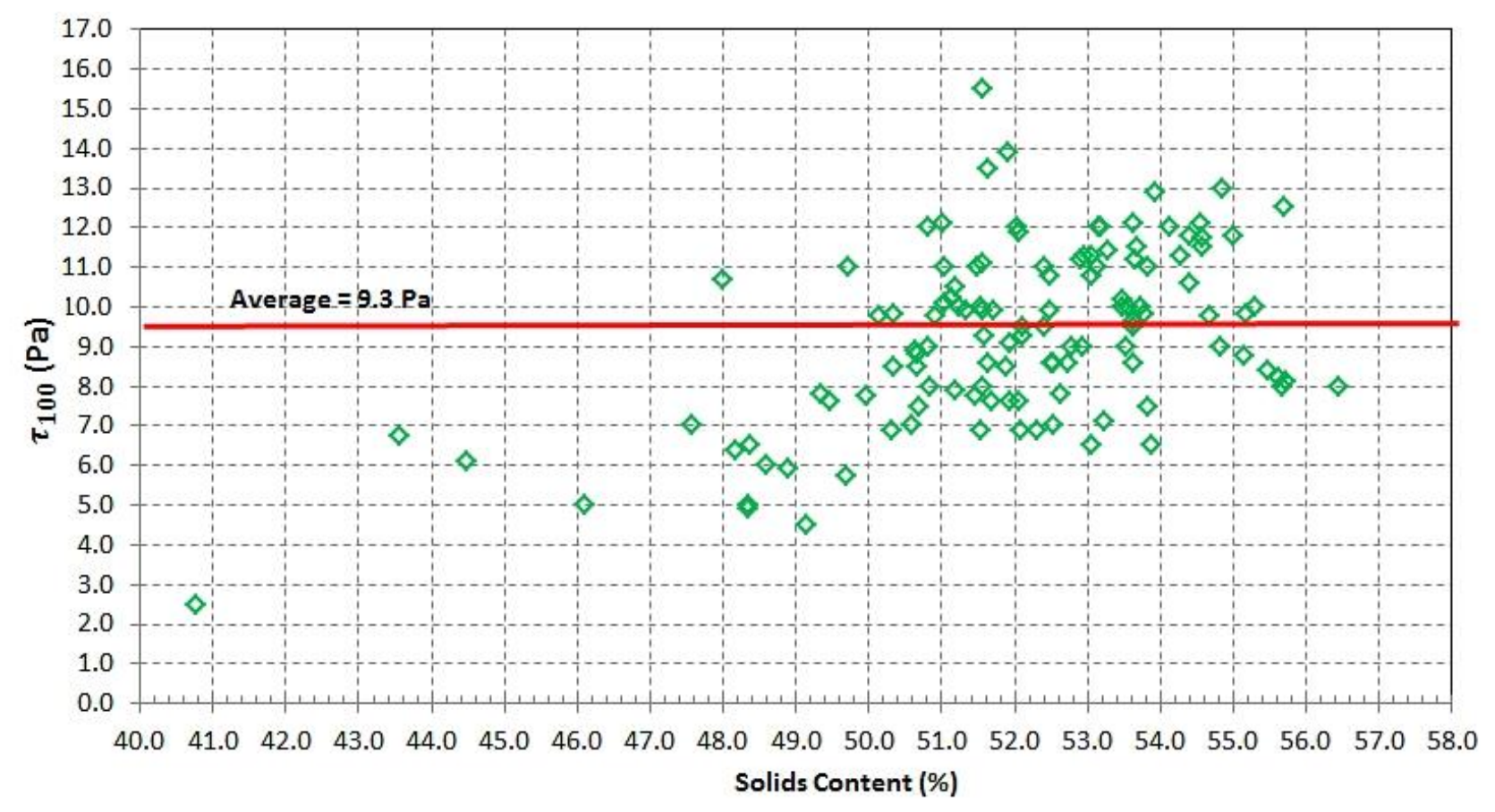

Figure 9 Rheology of the slurry received during the field trial period

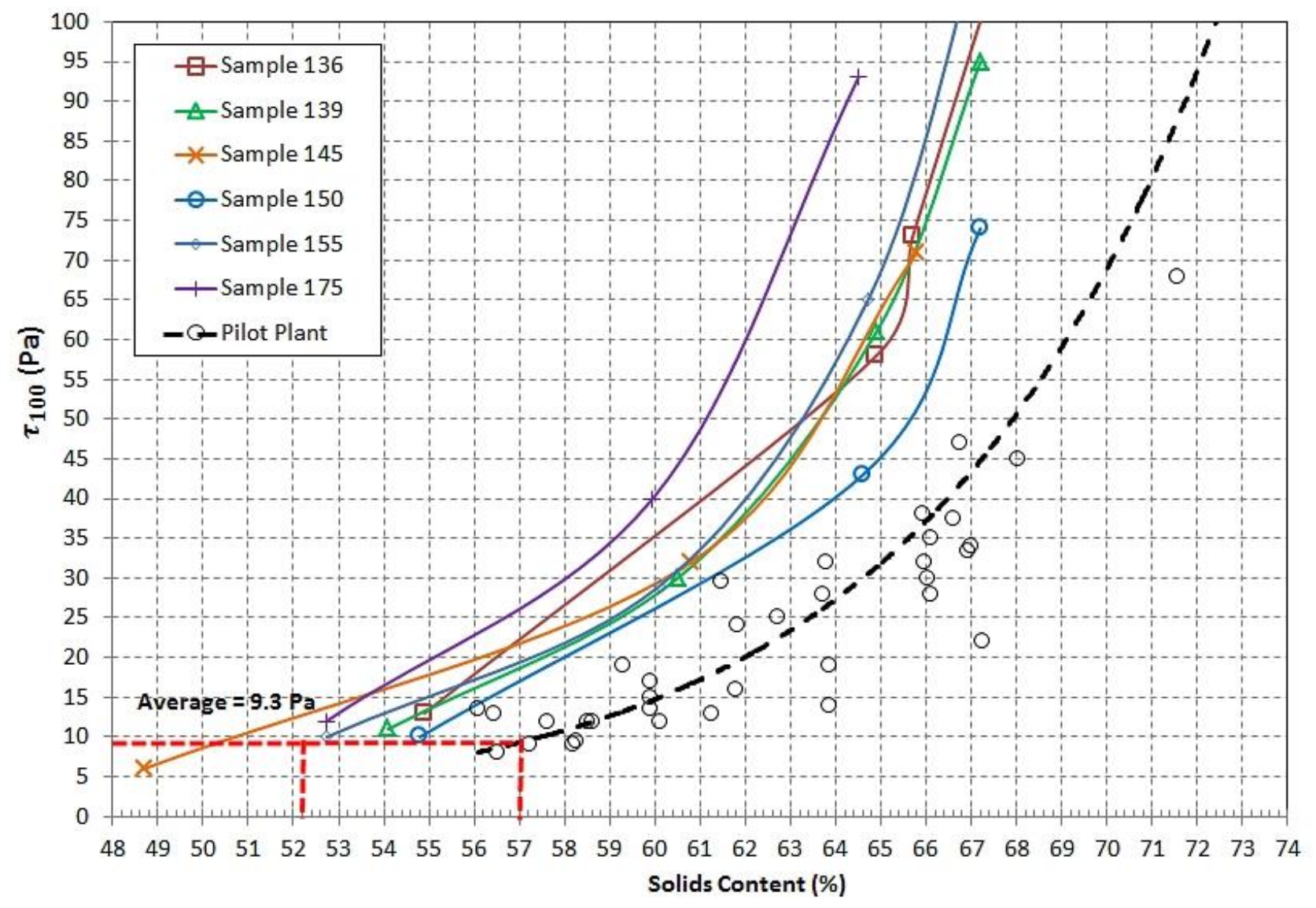

\section{Figure 10 Comparison of tailings rheology used at the pilot plant with the rheology of tailings used at the field trial}

The plot in Figure 10 also shows that the average $t_{100}$ of 9.3 Pa during the field trial at $52.1 \%$ solids is similar to the same $t_{100}$ at the average solids content of $57 \%$ during the pilot plant work. 


\section{Development of tailings beach and beach slope}

The development of the tailings beach with time and the mechanism of beach formation were accurately monitored during the field trial.

The observations showed that when the tailings stream from a discharge outlet reaches the surface of a deposition area for the first time, as expected, the flow initially spread itself out in the form of sheets and fans which provide a bed of fresh tailings.

As more time passes and the tailings flow continues, and as soon as a bed layer of sufficient thickness is created from newly deposited tailings, a narrow self-formed channel quite suddenly appears within the new, now stationary, laminar formed sheet, and the flow depth and velocity increases within this new channel. After the formation of this channel no further deposition of tailings occurs in the area where the channel has formed. The self-formed channels are simply a transport mechanism for the tailings to travel from the plunge pool to further downstream areas.

In other words, the deposition of tailings on the beach occurs only as a result of the sheet flow mechanism but the deposition in an area is limited to a depth sufficient only for a channel to form.

The plunge pool formation and self-formed channel development process is shows in Figure 11.
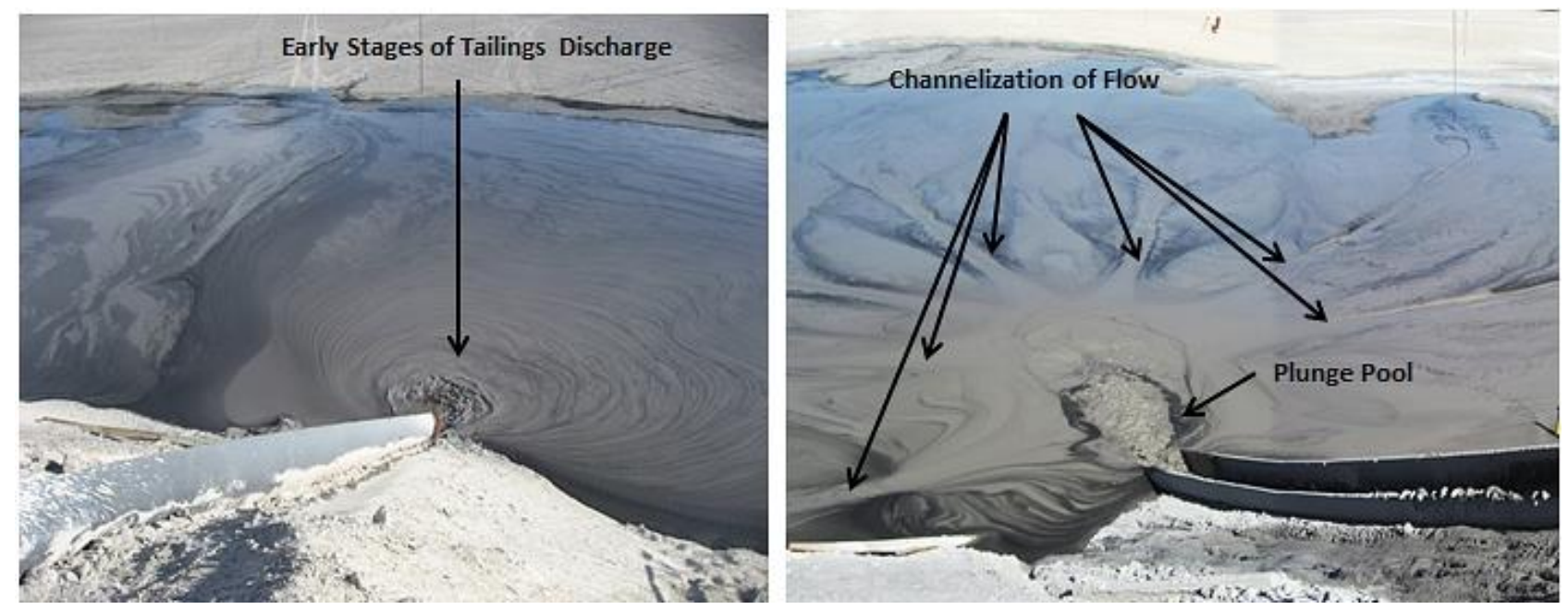

Figure 11 Formation of plunge pool and development of self-formed channels

A fully developed self-formed channel over the entire length of the beach is shown in Figure 12.

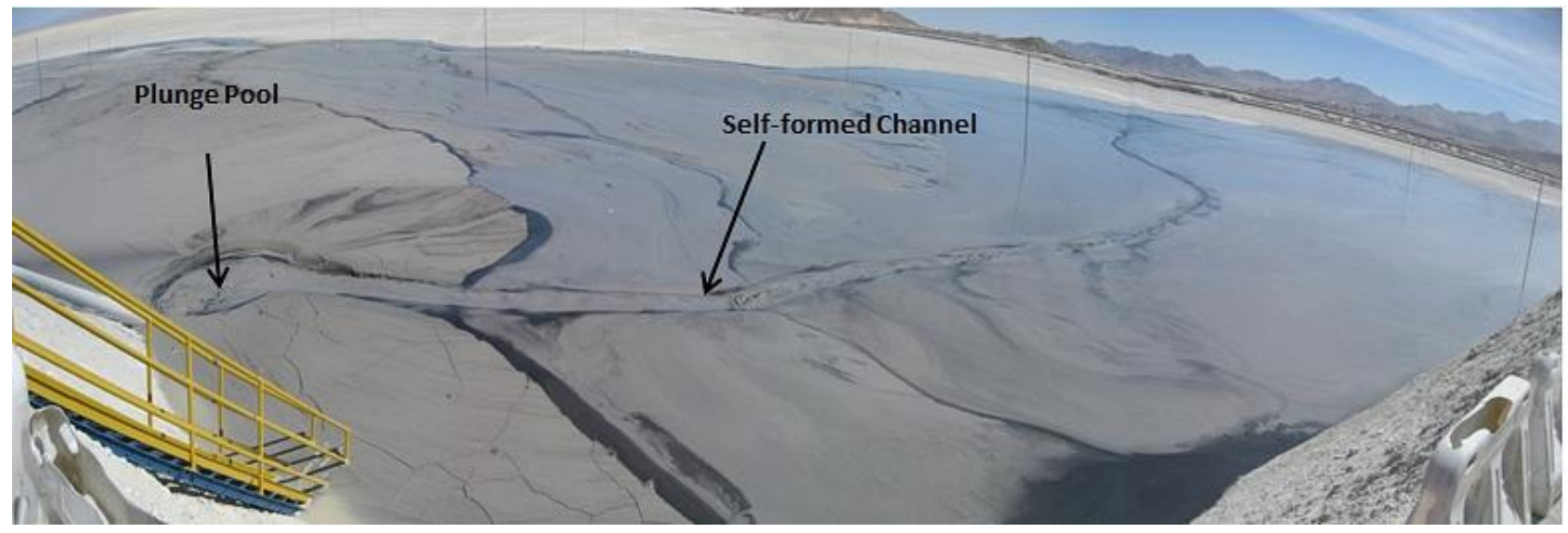

Figure 12 Fully developed self-formed channel over the entire length of the beach 
The beach development and expansion over the trial area were recorded on a daily basis. Figures 13 to 15 show three snapshots of the many surveys of the tailings beach carried out twice weekly using the 3D laser scanner. The surveys shown on these figures are with approximately one month time intervals. As would be expected, the footprint of the stack has expanded with time.

Figure 16 shows a cross section through the tailings stack. The tailings surface from the above mentioned three surveys are shown on this section.

The measured beach slope values for successive length intervals of $50 \mathrm{~m}$ from the discharge point are also shown in Figure 16 for each of the three surveys. As can be seen the beach slope increased with time. The improvement in beach slope continued until a certain point when the beach was fully developed. After this point the weekly consecutive surveys did not show any noticeable increase in beach slope. This condition was observed at about mid-October and it was decided that the trial could be terminated.

A shown in Figure 16 the developing beach always exhibited a concave profile. The steeper beach slope appeared closer to the discharge point with a maximum slope of $2.29 \%$ and the flatter beach slope formed at the downstream toe of the stack with a minimum value of $0.6 \%$.

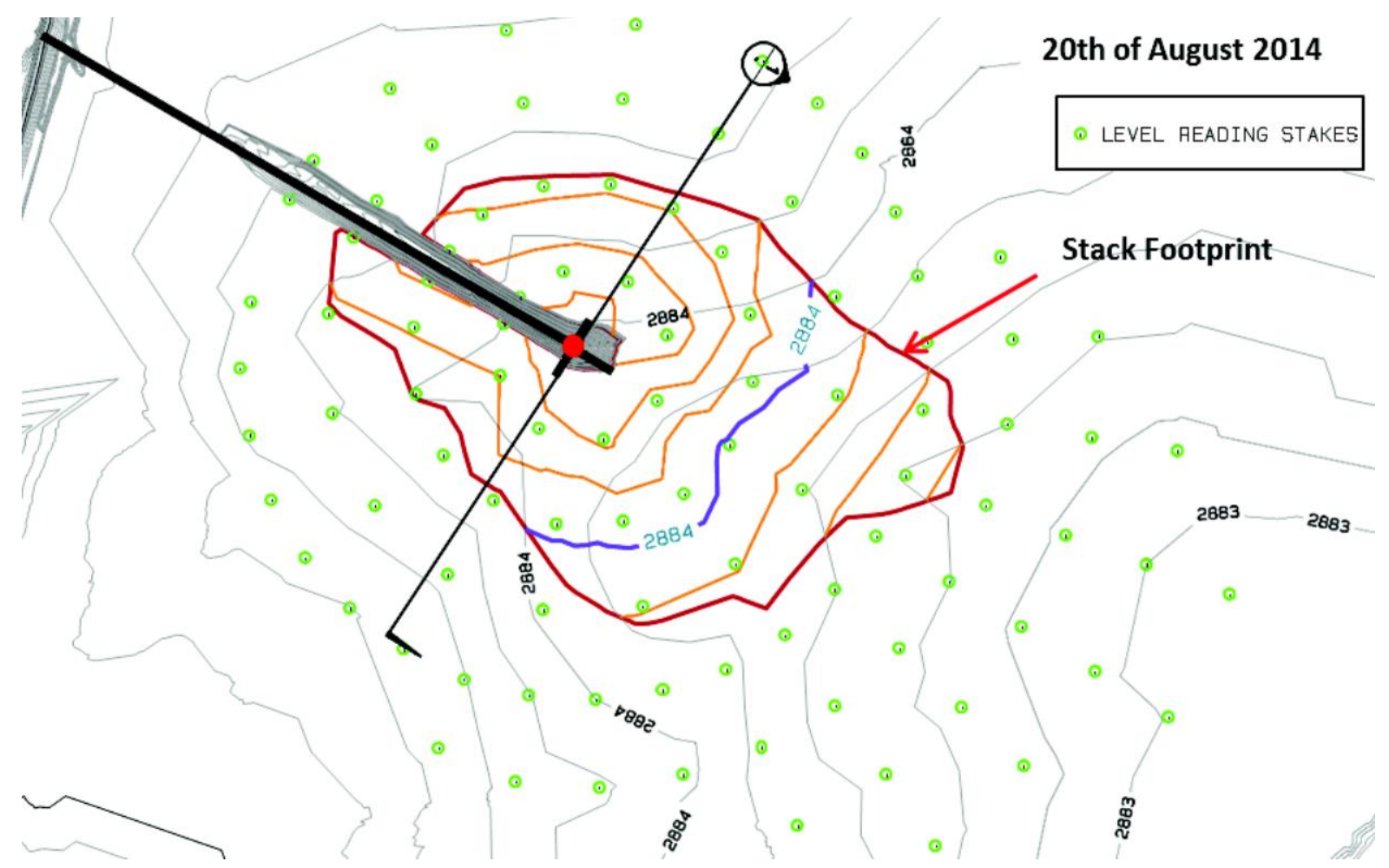

Figure 13 Tailings beach survey at 20 August 2014 


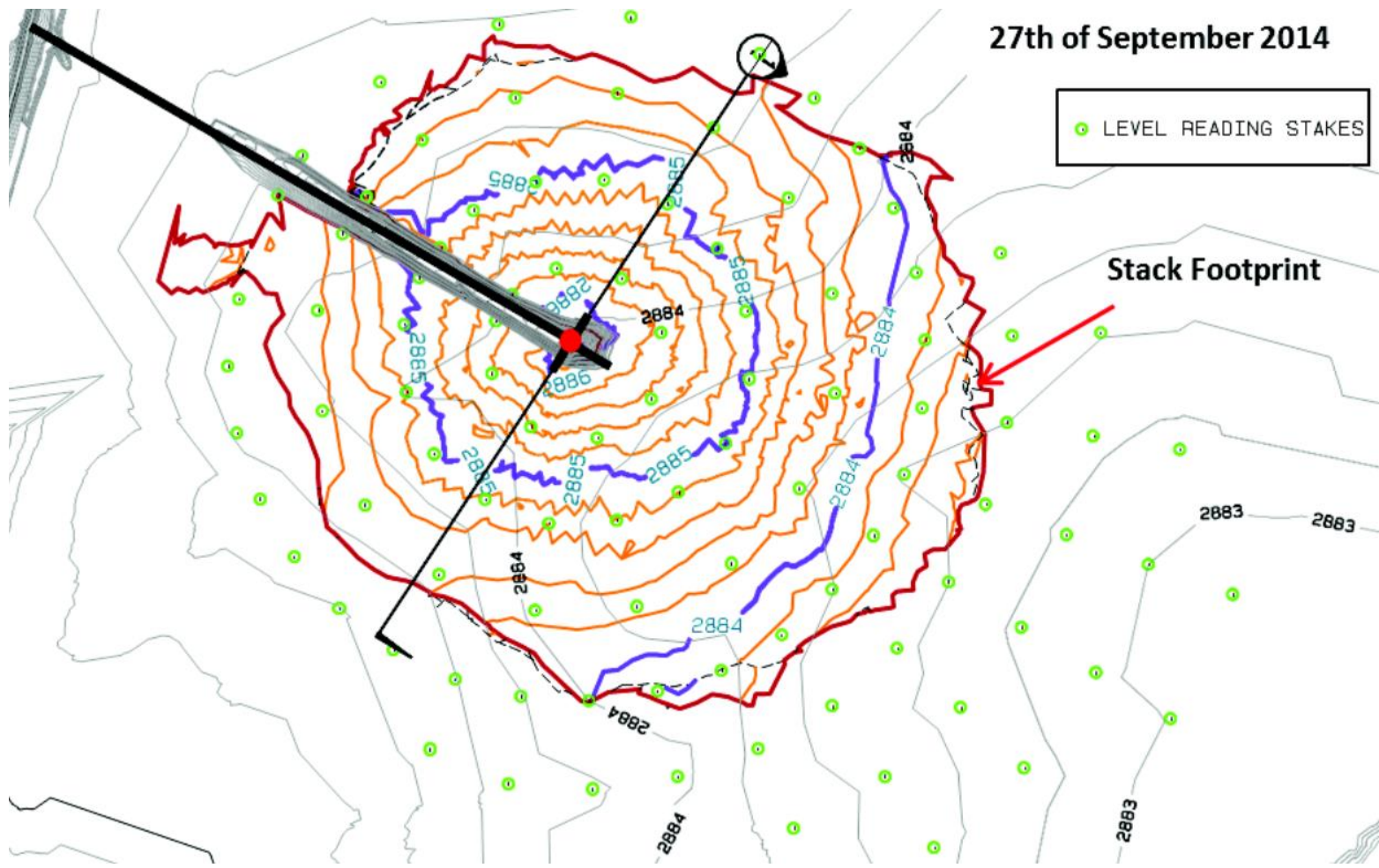

Figure 14 Tailings beach survey at 27 September 2014

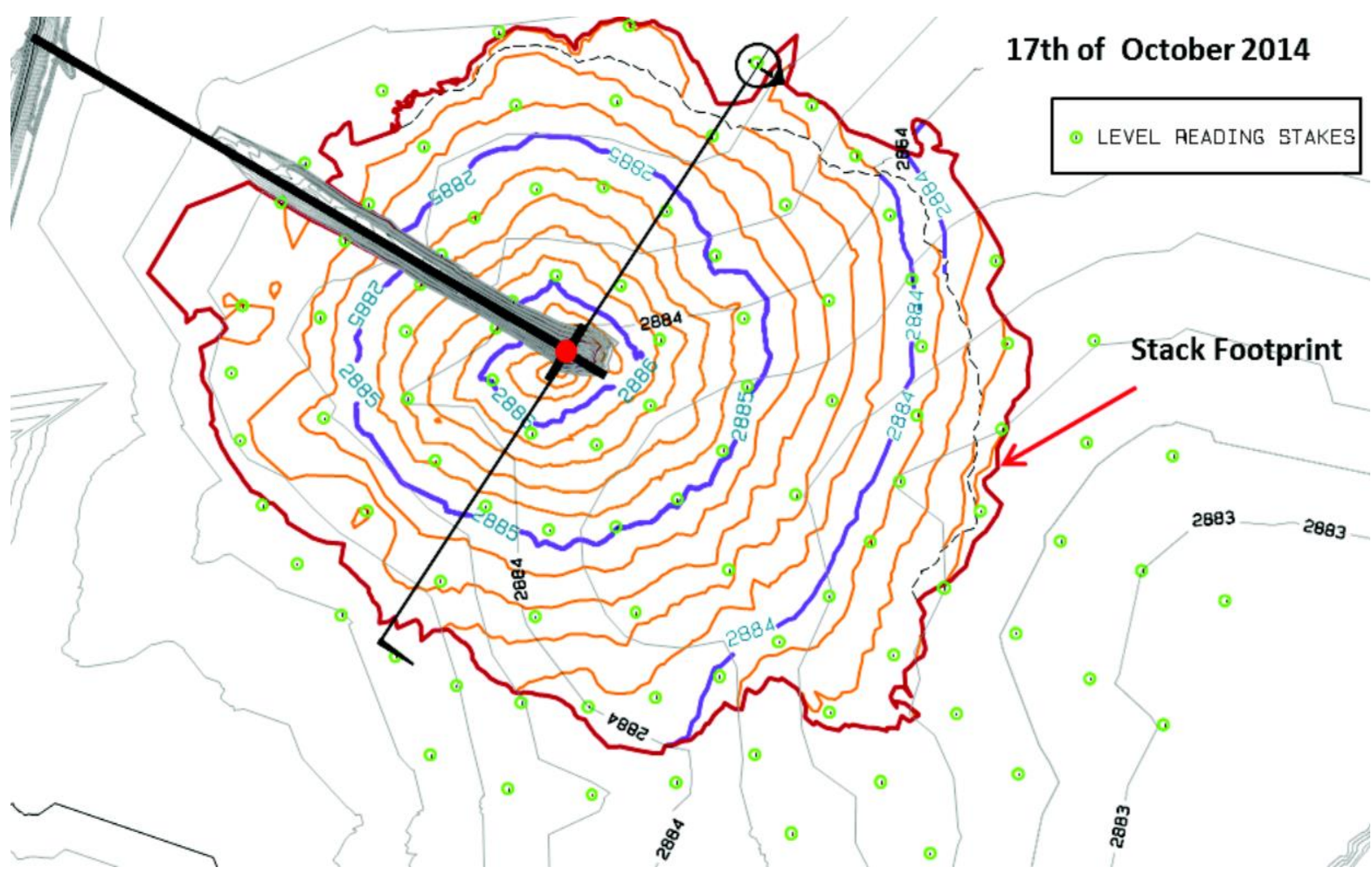

Figure 15 Tailings beach survey at 17 October 2014 


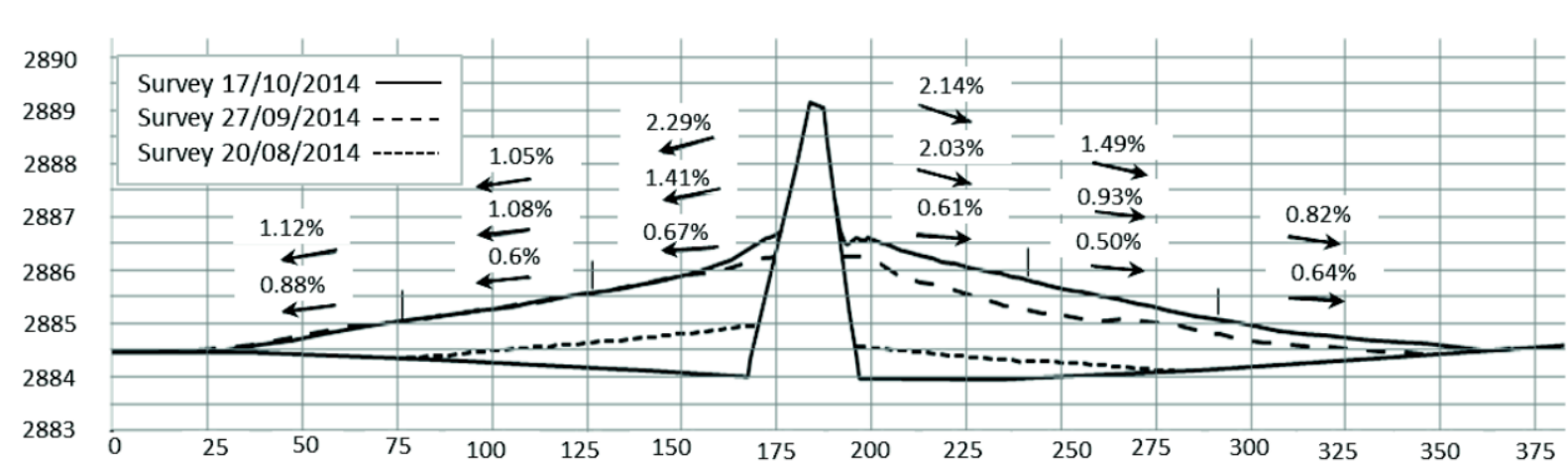

Figure 16 Profile view of the developed tailings beach over time

A concave profile is typical for thickened tailings stacking and is due to the following:

1. Variability in the slurry solids content and rheology. Tailings with lower rheology and solids content always travel furthest downstream and form a flatter beach slope while higher rheology and solids content will force the tailings to stack closer to the discharge point and form a steeper beach slope.

2. At any snapshot in time, the areas closer to the discharge point are where the beach is fully developed to its final profile (steeper beach slope) but in the areas further away from the discharge point the tailings is still depositing and the beach is still under development and hence these areas have flatter beach slope.

Figure 16 shows that the average achieved beach slope during the 56 days of the field trial with tailings at an average solids content of $52.1 \%$ (i.e. $t_{100}=9.3 \mathrm{~Pa}$ ) was about $1.5 \%$. This average beach slope value is consistent with the average 1.5\% beach slope predicted in 2011 for pilot plant tailings at a solids content of $57 \%$, which was also for a $t_{100}=9.3$ Pa for those tailings.

\section{$7 \quad$ Conclusions}

The following direct conclusions and remarks are derived from the observations and analysis of the data recorded during the Chuquicamata field trial:

- The beach formation always starts with laminar sheet fan flow expanding over the surface.

- At the discharge point the high velocity of the incoming tailings stream causes a plunge pool to form at the impact area.

- All the dynamic energy in the incoming stream (due to discharge pipe velocity and due to the elevation drop) is dissipated in the plunge pool. Higher energy in the discharge stream would simply mean a bigger plunge pool.

- The tailings flow that leaves the plunge pool and forms the beach does not have any memory of the amount of energy in the upstream flow stream from the outlet.

- As soon as a bed layer of sufficient thickness is created from newly deposited tailings, self-formed channels appear within the deposited material and the flow depth and velocity increase within these new channels. The flow in the channels is turbulent.

- Channelisation of flow prevents further lateral deposition of tailings by sheet and fan flow mechanisms. After development of the self-formed channels no further deposition of tailings occurs in the area where the channels have formed. The self-formed channels simply transport all of the tailings from the plunge pool to areas further downstream.

- In a trial with continuous discharge of tailings, and at a high enough flow for turbulent conditions to develop in the channel, the beach slope of the stack improves as time passes and the footprint 
area grows. This process continues until a point when the fully developed channelised flow has stabilised on the beach.

- The developing beach will always have a concave profile that reflects the variability of slurry rheology and flow rate that inevitably occur in practice.

- The results of the achieved beach slope during the field trial confirmed the validity of the beach slope prediction model used for the full-scale TSF design.

\section{Acknowledgement}

The authors would like to acknowledge the support of CODELCO-VP site personnel during the field trial test work and for the permission to publish the data in this paper.

The authors also would like to thank ATC Williams laboratory technician Peter Lam, ATC Williams site engineer Pablo del Río and all other site staff for their help and contribution during this field trial.

\section{References}

Fitton, TG, Williams, MPA, Seddon, KD, Bhattacharya, SN \& Chryss, AG 2007, 'Simulation of thickened tailings stacks', in AB Fourie \& RJ Jewell (eds), Proceedings of the 10th International Seminar on Paste and Thickened Tailings, Australian Centre for Geomechanics, Perth, pp. 305-313.

Pirouz, B, Kavianpour, MR \& Williams, P 2005, 'Thickened tailings beach deposition. Field observations and full-scale flume testing', in RJ Jewell \& S Barrera (eds), Proceedings of the 8th International Seminar on Paste and Thickened Tailings, Australian Centre for Geomechanics, Perth, pp. 53-72.

Pirouz, B \& Williams, P 2007, 'Prediction of non-segregating thickened tailings beach slope - a new method', in AB Fourie \& RJ Jewell (eds), Proceedings of the 10th International Seminar on Paste and Thickened Tailings, Australian Centre for Geomechanics, Perth, pp. 315-327.

Pirouz, B, Seddon, KD, Pavissich, C, Williams, P \& Echevarria, J 2013, 'Flow through tilt flume testing for beach slope evaluation at Chuquicamata Mine Codelco, Chile', in RJ Jewell, AB Fourie, J Caldwell \& J Pimenta (eds), Proceedings of the 16th International Seminar on Paste and Thickened Tailings, Australian Centre for Geomechanics, Perth, pp. 457-472.

Pirouz, B, Javadi, S, Seddon, KD \& Williams, MPA 2014, 'Modified beach slope prediction model for non-segregating thickened tailings', in RJ Jewell, AB Fourie, PS Wells \& D van Zyl (eds), Proceedings of the 17th International Seminar on Paste and Thickened Tailings, InfoMine Inc., Vancouver, pp. 31-46.

Williams, MPA \& Meynink, WJC 1986, 'Tailings beach slopes', Mine Tailings Disposal Workshop Notes, The University of Queensland, Brisbane.

Williams, MPA 2014, 'Channel hydraulics or deposition flume testing - which is right for beach slope forecasting, in RJ Jewell, AB Fourie, PS Wells \& D van Zyl (eds), Proceedings of the 17th International Seminar on Paste and Thickened Tailings, InfoMine Inc., Vancouver, pp. 3-18. 
